\title{
IMPROVING THE QUALITY OF LIFE IN PSORIASIS PATIENT THROUGH HEALTH PROMOTION APPROACH AT HAJI ADAM MALIK GENERAL HOSPITAL, MEDAN, INDONESIA
}

\author{
CASHTRY MEHER*, IRMA D ROESYANTO, KINTOKO ROCHADI, TAUFIK ASHAR
}

Departement of Health Promotion, Faculty of Public Health, Sumatera Utara University-Haji Adam Malik General Hospital, Medan, Indonesia. Email: cashtrymeher14@gmail.com

Received: 08 May 2018, Revised and Accepted: 06 June 2018

\section{ABSTRACT}

Objective: Psoriasis is a chronic inflammatory skin disease, can affect all ages characterized by reddish plaques that are covered by thick scales of silvery white and firmly bounded. Psoriasis is a skin disease that is difficult to cure because psoriasis can interfere with life quality of life behavior even cause the level of stress for the patient. This study aims to evaluate the effect of health promotion of quality of life of psoriasis patients.

Methods: This research is an experiment between pre- and post-test that aims to know the effort of improving the quality of life of psoriasis patient through a health promotion approach. Population in this research is patient of psoriasis in the draft of human rights number 60 people. Then, divide the questioner to the respondents who made twice before the health promotion and after health promotion in the experimental group.

Result: The study showed significant differences between pre- and post-test values for quality of life, stress level, and behavior toward health promotion. Data analysis with paired t-test at 95\% confidence level, quality of life with lecture method ( $p=0.001$ ), quality of life ( $\mathrm{p}=0.001$ ), and behavior with method of Booklet $(\mathrm{p}=0.001)$.

Conclusion: It is recommended for health workers more often to provide health promotion because psoriasis is chronic and recidive disease, it is necessary to improve the quality of service in hospitals by providing education in the form of health promotion in patients not to quickly despair and can comply with doctor's advice.

Keywords: Quality of life, Psoriasis, Dermatology life quality index, Health promotion.

(C) 2018 The Authors. Published by Innovare Academic Sciences Pvt Ltd. This is an open access article under the CC BY license (http://creativecommons. org/licenses/by/4. 0/) DOI: http://dx.doi.org/10.22159/ajpcr.2018.v11i10.27160

\section{INTRODUCTION}

Psoriasis is a chronic inflammatory skin disease, can affect all ages characterized by reddish plaques that are covered by thick scales of silvery white and firmly bounded. In general, psoriasis lesions are distributed symmetrically with predilection especially in the elbow and knee, scalp, lumbosacral, buttocks, and genitalia [1,16-18].

Psoriasis can interfere with the quality of life of patients this is because the treatment often does not provide a satisfactory outcome, resulting in social and economic burden. Various studies over the past few decades have added to the knowledge of the pathogenesis of psoriasis, with the ultimate goal of getting more effective therapy or healing, but to date, the exact cause is still unknown [2].

Consensus by the American Academy of Dermatology states that any determination of the severity of psoriasis requires special attention and its effect on the quality of life of the sufferer [3]. One technique used to measure the severity of psoriasis is using the psoriasis area and severity index [4]. Although susceptibility genes have been identified, there is still no satisfactory treatment [5]. The treatment can be done still limited to physical treatment, not mental recovery [6].

Psoriasis which is a skin disorder characterized by hyperproliferation and inflammation of the epidermis with a clinical picture of erythematous plaque and layered plaque, which is chronic. Psoriasis can affect $\pm 2.5 \%$ of the world's population, about $20-30 \%$ suffer from moderate to severe psoriasis [7]. Until now the exact cause of psoriasis is still debated, but some of the factors reported to worsen the condition of psoriasis include physical trauma, infection, stress, seasonal, and climatic changes, certain drugs, including lithium salts, beta blockers, and chloroquine antimalarials [8]. Similarly, alcohol consumption, smoking, and obesity may aggravate psoriasis or complicate the management of psoriasis [9].

Based on medical record data of Haji Adam Malik General Hospital Medan, Indonesia, showed the increasing trend of psoriasis cases, especially in the period 2013-2015. Data, in 2013, diagnosed with psoriasis patients 47 new patients and 31 recurrent patients, then in 2014 increased new patient with psoriasis, 56 new patients, and 27 recurrent patients. The re-increment occurred in the period 2015 with 69 new patients and 20 recurrent patients (Medical record data of Haji Adam Malik General Hospital). Based on medical record data above can be concluded that the decreased number of patients who do follow-up every year against psoriasis disease while the new case of the trend to increase.

Research on the quality of life of psoriasis patients has also been the concern of some previous researchers, including research on the quality of life of psoriasis patients in the Osmanabad region, India. The results showed that the quality of life was low and very disturbing in life compared to other healthy individuals [10]. Another study examined the quality of life in patients with psoriasis in tertiary care hospitals concluded that psoriasis is a chronic recurrent disease and has a significant negative impact to the quality of life of the patient [11].

The common thing that is often found in people with psoriasis is despair of the disease because it cannot be cured so that sometimes occur psychological disorders and decreased the quality of life. Breaking expectations have an impact on mental health and quality of life so that it unknowingly affects the emergence of various other health problems. Psoriasis indirectly causes death, but the effects of discomfort and length of the healing process have a serious impact on quality of life. Based on this phenomenon, researchers intend to know the implementation 
of the most effective health promotion model in support of efforts to improve the quality of life of patients with psoriasis.

In harmony with the impact of psoriasis on quality of life, the researchers gave the idea that it is necessary to approach health promotion in the form of health education so that various physical and mental impacts can be minimized. This idea is encouraged because as far as the researcher's observation the attention of the treatment is still limited to pay attention to physical impact regardless of mental state. Although psoriasis generally does not cause death give a very great impact to quality of life of the sufferer, hence need to be done effort to improve quality of life through health promotion approach in the form of empowerment and health education.

\section{METHODS}

Study design using an experimental model with quasi-experimental type with Non-Equivalent Control Group design aimed to know the effort to improve the quality of life of psoriasis disease using health promotion method at Haji Adam Malik General Hospital Medan. Sample recruitment using consecutive sampling method from patient recorded in the medical record of Haji Adam Malik General Hospital.

The inclusion criteria are patient with a diagnosis of psoriasis, willing to follow the stages of research, age above 18 years old. The exclusion criteria in this research are respondents who did not willing to participate in the research stages. Quality of life assessment is done using the dermatology life quality index (DLQI), giving education is divided into three methods such as use lectures, booklets, and social media. Group receiving intervention was divided using the simple random method, and then made a comparison between the change of life quality before and after the intervention. Statistical analysis used is a normality test to find out data distribution and paired sample t-test to compare the quality of life before and after the intervention.

\section{RESULTS}

This study used 60 psoriasis patients who were divided into three groups equally, namely group lectures, booklet groups, and social media groups. Subject characteristics are shown in Table 1.

Based on Table 1, the age group of patients with psoriasis was the most in the range of 35-40 years, women tend to be more affected by psoriasis which is 35 people (58.3\%), and the majority of research subjects have senior education in high school as many as 42 people $(70 \%)$.

A description of the quality of life before and after the intervention can be shown in Tables 2 and 3 .

In Table 2, it was found that the quality of life of the majority of respondents was disrupted, namely for the lecture group as much as 16 respondents (80\%), for Booklet group as many as 15 respondents (75\%), and for social media group as many as 11 respondents (55\%). The result of the research on psoriasis patient after getting health promotion got DLQI with an average degree of disturbance of quality of life is 28.52 (slightly disturbed).

In Table 3, it is found that the quality of life of the respondents after getting the health promotion of the majority is slightly disturbed for the lecture group as much as 11 respondents (55\%) and uninterrupted 6 respondents (30\%), for booklet group as many as 12 respondents $(60 \%)$, and group social media as much as 16 respondents $(80 \%)$.

\section{Normality test}

Normality test is a requirement that must be fulfilled using t-test. The test of normality aims to find out whether the data used is normally distributed using Kolmogorov-Smirnov test. Based on the normality test on the variable of quality of life with lecture method, booklet, and social media, it is obtained that some normally distributed variables with p>0.05 (Table 4).
Influence of media model lecture on the quality of life of psoriasis patients

Because the data is normally distributed so that paired sample t-test is used to compare the quality of life in conditions before and after intervention.

The result of calculation influence of lecture media model to the quality of life, behavior, and stress degree of psoriasis patient is shown in Table 5 .

Based on Table 5, there was an improvement in DLQI score after lecture media model intervention from 22.80 (disrupted) to 30.55 (slightly disrupted). The result of paired t-test is obtained $p<0.001$ which means there is difference in dermatology quality of life index of person living with psoriasis before and after get health promotion with lecture method. This

Table 1: Subject characteristics

\begin{tabular}{ll}
\hline Characteristics & Frequency (\%) \\
\hline Age (years) & \\
$<35$ & $22(36.67)$ \\
$35-40$ & $24(40)$ \\
$40-45$ & $14(23.33)$ \\
Gender & $25(41.67)$ \\
$\quad$ Male & $35(58.33)$ \\
Female & $10(16.67)$ \\
Educational level & $42(70)$ \\
Junior high school & $8(13.33)$ \\
Senior high school & \\
Higher education &
\end{tabular}

Table 2: DLQI before health promotion

\begin{tabular}{lll}
\hline Health promotion type & Quality of life & Frequency (\%) \\
\hline Before health promotion & Not disturbed & $0(0)$ \\
(lectures method) & Slight disturbed & $4(20)$ \\
& Moderately disturbed & $16(80)$ \\
& Very disturbed & $0(0)$ \\
& Total & $20(100)$ \\
Before health promotion & Not disturbed & $0(0)$ \\
(booklet method) & Slight disturbed & $2(10)$ \\
& Moderately disturbed & $15(75)$ \\
& Very disturbed & $3(15)$ \\
Before health promotion & Total & $20(100)$ \\
(social media method) & Notisht disturbed & $0(0)$ \\
& Moderately disturbed & $2(10)$ \\
& Very disturbed & $7(55)$ \\
& Total & $20(100)$ \\
\hline
\end{tabular}

DLQI: Dermatology life quality index

Table 3: DLQI after health promotion

\begin{tabular}{lll}
\hline Health promotion type & Quality of life & Frequency (\%) \\
\hline Before health promotion & Not disturbed & $6(30)$ \\
(lectures method) & Slight disturbed & $11(55)$ \\
& Moderately disturbed & $3(15)$ \\
& Very disturbed & $0(0)$ \\
& Total & $20(100)$ \\
Before health promotion & Not disturbed & $0(0)$ \\
(lectures method) & Slight disturbed & $12(60)$ \\
& Moderately disturbed & $8(4)$ \\
& Very disturbed & $0(0)$ \\
Before health promotion & Total & $20(100)$ \\
(lectures method) & Not disturbed & $0(0)$ \\
& Slight disturbed & $16(80)$ \\
& Moderately disturbed & $3(15)$ \\
& Very disturbed & $1(5)$ \\
& Total & $20(100)$ \\
\hline
\end{tabular}

DLQI: Dermatology life quality index 
Table 4: Normality test

\begin{tabular}{|c|c|c|c|c|c|c|}
\hline \multirow[t]{3}{*}{ Variable } & \multicolumn{6}{|c|}{ Health promotion model } \\
\hline & \multicolumn{2}{|l|}{ Lecturer } & \multicolumn{2}{|l|}{ Booklet } & \multicolumn{2}{|c|}{ Social media } \\
\hline & p-value & Index & p-value & Index & p-value & Index \\
\hline \multicolumn{7}{|l|}{ Life quality DLQI } \\
\hline Before intervention & 0.894 & Normal & 0.405 & Normal & 0.277 & Normal \\
\hline After intervention & 0.653 & Normal & 0.486 & Normal & 0.178 & Normal \\
\hline \multicolumn{7}{|l|}{ Life quality } \\
\hline Before intervention & 0.975 & Normal & 0.837 & Normal & 0.766 & Normal \\
\hline After intervention & 0.179 & Normal & 0.966 & Normal & 0.185 & Normal \\
\hline
\end{tabular}

DLQI: Dermatology life quality index

Table 5: Influence of media model lecture on the quality of life of psoriasis patients

\begin{tabular}{lcc}
\hline Variable & Mean \pm SD & p-value \\
\hline Life quality DLQI & & \\
$\quad$ Before intervention & $22.80 \pm 3.65$ & $<0.001^{* *}$ \\
After intervention & $30.55 \pm 4.04$ & \\
Life quality & & \\
$\quad$ Before intervention & $59.60 \pm 5.98$ & $<0.001^{* *}$ \\
After intervention & $81.15 \pm 7.63$ & \\
\hline **Significant. DLQI: Dermatology life quality index, SD: Standard deviation
\end{tabular}

Table 6: Influence of media booklet model on quality of life of psoriasis patients

\begin{tabular}{lcc}
\hline Variable & Mean \pm SD & p-value \\
\hline Life quality DLQI & & \\
Before intervention & $20.60 \pm 3.23$ & $<0.001^{* *}$ \\
After intervention & $26.95 \pm 3.70$ & \\
Life quality & & $<0.001^{* *}$ \\
Before intervention & $61.10 \pm 4.86$ & \\
After intervention & $74.40 \pm 8.70$ & \\
\hline
\end{tabular}

**Significant. DLQI: Dermatology life quality index, SD: Standard deviation

Table 7: Influence of social media model on quality of life, behavior, and degree of stress of psoriasis patients

\begin{tabular}{lcc}
\hline Variable & Mean \pm SD & p-value \\
\hline $\begin{array}{l}\text { Life quality DLQI } \\
\text { Before intervention }\end{array}$ & $18.75 \pm 3.58$ & $<0.001^{* *}$ \\
After intervention & $28.05 \pm 4.80$ & \\
Life quality & $62.65 \pm 5.08$ & $<0.001^{* *}$ \\
Before intervention & $74.95 \pm 6.09$ & \\
After intervention & & \\
\hline
\end{tabular}

**Significant. DLQI: Dermatology life quality index, SD: Standard deviation

means that there is a significant influence of the lecture media model on the dermatology quality of life index of people living with psoriasis.

The average value of quality of life before given lecture method is 59.60 (moderate) and after lecture, an increase is 81.15 (Good). The result of paired t-test is obtained $\mathrm{p}<0.001$ which means there is the difference in the quality of life of person living with psoriasis before and after get health promotion with the method of lecture. This means there is a significant influence of media model of lecture to the quality of life of psoriasis patient (Table 4).

Influence of media booklet model on quality of life of psoriasis patients

Based on the results of the analysis with paired t-test test obtained results improved quality of life, behavior, and degree of stress psoriasis patients through health promotion approach with booklet media. The result of calculation influence of booklet media model to the quality of life, behavior, and stress degree of psoriasis patient is shown in Table 6 .

In Table 6, the mean value of the dermatology quality of life index was given before booklet method 20.60 (disturbed) and after the booklet method was given an increase of 26.95 (slightly disturbed). The result of paired t-test is obtained $\mathrm{p}<0.001$ which means there is difference of dermatology quality of life index of person living with psoriasis before and after get health promotion by booklet method. This means that there is a significant effect of media booklet model on the dermatology quality of life index of people living with psoriasis.

The average value of quality of life before given method of the booklet is 61.10 (moderate) and after given booklet there is an increase that is 74.40 (Good). The result of paired t-test is obtained $p<0.001$ which means there is difference in the quality of life of psoriasis patient before and after get health promotion by booklet method. This means there is a significant influence model of booklet media on the quality of life of psoriasis patients (Table 6).

Influence of social media model on quality of life, behavior, and degree of stress of psoriasis patients

Based on the results of the analysis with paired t-test results obtained results improved quality of life, behavior, and degree of stress psoriasis patients through health promotion approach with social media. The result of calculation of influence of social media model to quality of life, behavior, and stress degree of psoriasis patient is shown in Table 7.

In Table 7, the mean value of the dermatology quality of life index was given before the 18.75 (disrupted) booklet method and after the social method was given an increase of 28.05 (slightly disturbed). The result of paired t-test is obtained $\mathrm{p}<0.001$ which means there is difference of dermatology quality of life index of psoriasis sufferer before and after get health promotion with the social method. This means that there is a significant effect of social media model on the dermatology quality of life index of psoriasis patients.

The average value of quality of life before given the social method that is 62.65 (mediocre) and after being given a booklet an increase of 74.95 (Good). The results of paired t-test test results obtained $\mathrm{p}<0.001$ which means there are differences in quality of life of psoriasis patients before and after getting health promotion by social methods. This means there is a significant effect of social media model on the quality of life of psoriasis patients (Table 7).

\section{Multivariate analysis}

Multivariate analysis was used to determine the quality of life comparison between intervention groups, used to assess the most effective methods of improving quality of life. Multivariate analysis is shown in Table 8.

Based on Table 8, there are a significant difference in quality of life and DLQI between group intervention (lecture, booklet, and social media) $(p<0.05)$. If seen from the average value can be explained that 
Table 8: Comparison of health promotion model for quality of life improvement in psoriasis patient

\begin{tabular}{llll}
\hline Variable & Mean \pm SD & F & p-value \\
\hline Life quality DLQI & & & \\
$\quad$ Lecturer method & $30.55 \pm 4.04$ & 3.838 & $0.027^{*}$ \\
$\quad$ Booklet method & $26.95 \pm 3.70$ & & \\
$\quad$ Social media method & $28.05 \pm 4.80$ & & \\
Life quality & & & \\
$\quad$ Lecturer method & $81.15 \pm 7.63$ & 4.922 & $0.011^{*}$ \\
$\quad$ Booklet method & $74.40 \pm 8.78$ & & \\
Social media method & $74.95 \pm 6.09$ & & \\
*Significant, DLQI: Dermatology life quality index & &
\end{tabular}

*Significant, DLQI: Dermatology life quality index

the DLQI sufferers of psoriasis after being given health promotion with media model lecture is better than the media booklet and social media. Where the average DLQI of psoriasis patients after being given health promotion with media lecture model is 30.55 higher than media booklet 26.95 and social media 28.05 .

The improved quality of life can be explained that there are differences in the quality of life of psoriasis patients who are given health promotion with lecture media, booklet media, and social media with a value of $\mathrm{F}$ is 4.922 with $p=0.011(p<0.05)$. If seen from the average value can be explained that the quality of life of psoriasis patients after being given health promotion with media model lecture is better than the media booklet and social media. Where the average quality of life of psoriasis patients after being given health promotion with media lecture model is equal to 81.15 higher than media booklet 74.40 and social media 74.95 (Table 8).

\section{DISCUSSION}

Psoriasis is a stress-related disease; there is a close relationship between psoriasis and stress, which causes various clinical consequences. This suggests that psoriasis can be triggered by stress, leading to an increase in disease severity and a less than satisfactory outcome of therapy. A study conducted by Yang and Yang on the quality of life of psoriasis patients in Taiwan, which compares the quality of life of patients with psoriasis and other skin diseases. Patients with psoriasis tend to have frustration, depression, and greater shyness. Also regarding the social function of patients with psoriasis tend to have difficulty to interact with others, the fear to meet others, and difficulty to interact in work. Overall, it makes patients with psoriasis have a much lower quality of life compared to other skin diseases [11]. Another study by Garcia et al., who evaluated the quality of life in patients with psoriasis in Spain. The study found mean DLQI score was 12 , so it can be concluded that patients with psoriasis experience a severe disability $[12,13]$.

Patients with psoriasis experienced problems with interpersonal and stigmatic conditions, in one survey, $27 \%$ of psoriasis patients experienced difficulty in sexual activity, $81 \%$ experienced a shame when psoriasis was seen by others, and $88 \%$ were very worried about worsening of the disease. In addition to the stigma experienced also need to be considered, stigma is an attitude by the public against a condition and also the behavior of discrimination against patients with psoriasis which will cause psychological stress and disability of the patient [14]

In this study proved the existence of an improvement after the health promotion of the quality of life of patients with psoriasis. This is allegedly due to a change in the process of thinking of psoriasis disease, so this provides a change in the psychological mindset that can accept the continuity of life with the disease and a deeper knowledge of the disease itself $[14,15]$.

\section{CONCLUSION}

Patients with psoriasis tend to have moderate impairment regarding the quality of life as measured using the DLQI, teaching-based health promotion Interventions, social media, and booklets can improve the quality of life in patients with psoriasis.

\section{AUTHOR'S CONTRIBUTION}

All authors contributed to all of the writing process of this article.

\section{CONFLICTS OF INTEREST}

Authors have no conflicts of interest regarding all elements in this study.

\section{REFERENCES}

1. Wolff K, Goldsmith LA, Katz SI, Gilchrest BA, Paller AS, Leffell DJ, editors. Fitzpatrick's Dermatology in General Medicine $8^{\text {th }}$ edition. New York: McGraw-Hill; 2008.

2. Krueger JG. The immunologic basis for the treatment of psoriasis with new biologic agents. J Am Acad Dermatol 2002;46(1):19-23.

3. Feldman S, Krueger G. Psoriasis assessment tools in clinical trial. Ann Rheum Dis 2005;64: 65-8.

4. Basko P, Juliana L, Petronic-RV. Psoriasis: epidemiology, natural history, and differential diagnosis. Psoriasis: Targets and Therapy 2012;2(1):67-76

5. Smith CH, Anstey AV, Baker JN, Burden AD, Chalmers RJ, et al. British association of dermatologist guidelines for use of biological interventions in psoriasis 2005. Br J Dermatol 2005;153(3):486-87.

6. Orgaz MJ, Buendia EA, Arrabol PMA, Ruiz JC, Arias SS. Deficiency of serum concentration of 25-hydroxyvitamin D in psoriatic patient: a case-control study. J Am Acad Dermatol 2012; 67(5):931-08.

7. Dogra S, Yadav S. Psoriasis in India: prevalence and pattern. Indian J Dermatol Venereol Leprol 2010;76(2):595-600.

8. Brezinski EA, Follansbee MR, Armstrong EJ, Armstrong AW. Endothelial dysfunction and the effects of TNF inhibitors on the endothelium in psoriasis and psoriatic arthritis: a systematic review. Curr Pharm Des 2014;20(2):513-28.

9. Diluvio L, Vollmer S, Besgen P, Ellwart JW, Chimenti S, Prinz JC. Identical TCR beta-chain rearrangements in streptococcal angina and skin lesions of patients with psoriasis vulgaris. J. Immunol 2006;176(2):7104-11

10. Hamada IR, Al Raddadi AA, Bahamdan KA, Fatanil MI, Al Rakban AM, et al. Saudi practical guidelines on biological treatment of psoriasis. J Dermatolog Treat 2015;26(3):223-9.

11. Coates LC, Kavanaugh A, Mease PJ, Soriano ER, Laura AF, Armstrong AW, et al. Group research and assessment of psoriasis and psoriatic arthritis 2015 treatment recommendations for psoriatic arthritis. Arthritis Rheumatol 2016;69(5):1060-71.

12. Yang HJ, Yang KC. Impact of psoriasis on quality of life in Taiwan. Dermatologica Sinica 2015;33(1):146-50

13. Garcia EM, Santiago SA, Salas VI, Colmenero CG, Mellado VG, Eisman AB. Quality of life in person living with psoriasis patients. J Am Acad Dermatol 2014;7(2):1-6.

14. Fortune DG, Richards HL, Griffiths CEM. Psychological factors in psoriasis: consequences, mechanism, and interventions. Dermatol Clin 2005;23(1):681-94.

15. Bradford NK, Chan RJ. Health promotion and psychological interventions for adolescent and young adult cancer survivors: A systematic literature review. Cancer Treatment Reviews 2017:55(1):57-70

16. Sholiman GM, Osman SK, Hamdan AM. Preparation and evaluation of anthralin biodegradable nanoparticles as a potential delivery system for the treatment of psoriasis. Int J Pahrm Pharm Sci 2015;7(12):36-40.

17. Gizawa SE, Fadel M, Mourad B, Elnaby FEZ. Betamethasone dipropionate gel for treatment of localized plaque psoriasis. Int J Pharm Pharm Sci 2018;9(8):173-82.

18. Abdelgawad R, Nasr M, Hamza MY, Awad GAS. Topical and systemic dermal carriers for psoriasis. Int J Curr Pharm Res 2016;8(1):4-9. 